\title{
The Target Calculation in the Context of Strategic Management - A Conceptual Basis
}

\author{
Dr. Rayna Petrova \\ (Assistant Professor, Department of Finances and Accounting, \\ St. Cyril and St. Methodius University of Veliko Turnovo, Bulgaria)
}

\begin{abstract}
The concepts of strategic concurrent environment oriented management are applied in Strategic management accounting. The interest in the strategic aspects of accountability is enhanced by the increasing the role of some issues related to the strategy development of the company. This article is aimed at revealing the strategic aspects of the target calculation leading to improving performance, processes and internal environment of the companies.
\end{abstract}

Keywords: target costing, strategic management accounting, strategic management, accounting information

\section{Introduction}

The interest in the strategic aspects of accountability is enhanced by the increasing the role of some issues related to the strategy development of the company. The main reason for establishing the Strategic management accounting (SMA) is undoubtedly the emergence and development of strategic management. The strategic management represents generally an integrated approach to working out and implementing a strategy.

The concepts of strategic concurrent environment oriented management are applied in SMA. The difference could be summarized ${ }^{1}$ in view of the fact that the management accounting consider them from the position - how to obtain the necessary information, how to handle it and to whom it has to be provided. The strategic management is mainly focused on how to use the information to control economic units.

The target calculation is defined as a tool used for cost control throughout the whole product life cycle. The main goal of the method is to determine such price of the offered product that generates the desired profit.

This article is aimed at revealing the strategic aspects of the target calculation leading to improving performance, processes and internal environment of the companies.

\section{A conceptual basis of the target calculation}

The need for introduction the target calculation in $1960^{\text {th }}$ in Japan is connected with the rapidlychanging conditions of the external business environment, which in turn require economic units to adapt to them. This method is crucial for the organizations in the present time in order to achieve cost reduction and do profit planning. This importance is derived from the basic features of the modern industrial environment in which this method can work best: intense competition, rapidly evolving technologies and expertise, consumer awareness and increased desires and needs and more. Practices applied till now no longer correspond to the increased needs of the external environment. In response to these external changes within the organizations the process of development and reorganization begins as well as improvement of techniques and management of the production process practices, in order to keep its competitive advantage and cross their own interests with those of the market. Since its establishment the method of target calculation has found many supporters, mostly large companies $^{2}$ from the automotive and electronics industry, which have proven by their adequate behavior that come up to the dynamic market conditions.

It can be accepted that the method of target calculation represents a concept of planning, management and cost control, which is used in advance at the earliest stage of the enterprise life cycle where the product and its production processes are designed in order to affect the structure of expenditures in accordance with the market requirements.

A common and well-accepted definition of the method is given by the Consortium for Advanced Manufacturing International (CAM-I). According to this definition, on one hand the target calculation is a system designed to profit, on the other hand - it is a system directed to cost management, led by customersfocused price, centered on a design, comprising different functions. The target calculation starts working as an expenditure management tool at the first stage of product development and is applied throughout the whole life

\footnotetext{
${ }^{1}$ M. Pavlova, The activity of universities in a competitive environment and the role of management accounting, University Publishing House "St. St. Cyril and Methodius", Veliko Tarnovo, 2012, p. 28.

${ }^{2}$ Companies that apply the method and have the large share to the world market as Toyota, Nissan, Sony, Canon and others. 
cycle through the active participation of the value chain ${ }^{3}$. The target calculation aims to determine that level of expenditure which ensures a certain level of profit and market price, i.e. its goal is satisfying the interests of both sides - the enterprise and the customers. It is used while introducing a new product on the market. It is a method of determining the acceptable level of product production costs under certain market price and quality level as well as profit expected by the managers. The main engine is the market. Not the enterprise, but consumers determine the price at which the products would have been purchased by them at a certain level of quality. In the core of this method of calculation are the consumers. This is not only a method of calculating but also a method of strategic planning.

Undoubtedly, the target calculation is driven by price - the essence of this idea is the following: first an company obtains outside information about the competitive market price, then the desired profit is subtracted from it and the difference between these two values represents a permissible level of product production cost. What has been said can be illustrated by the following scheme:

\section{- Target price}

- Target profit margin

\section{- Target costs ( Target price - Target profit margin)}

The target price, also called competitive market price within the enterprise is an independent variable. This means that the enterprise can not influence this price and its size can be changed only by external factors the market conditions and the desires of consumers.

The target profit margin within the enterprise is a dependent variable. It is closely linked with the wishes of the management for effective and efficient functioning of the enterprise. The size of this variable depends on factors internal for the enterprise. One of these factors might be the desire for accumulating more financial resources in order to expand the business activities.

The size of the target costs depends on both the competitive market price and the expected profit, i.e. it depends on both the external and internal factors. There are various options. If the income of the consumer increases, he/she tends to pay a higher price for a product with a certain level of quality, and if the company considers that realized until now profit is sufficient. This leads to an increased cost which is needed to produce the product. The consequence may be increasing the product quality. Another option is the increased market price to generate in the enterprise management, a desire for increasing profits. The important thing here is that the management should afford increasing profits at a rate not exceeding that of the price increase. Otherwise, the allowable cost will be reduced and there will be difficult to produce the product on the current level of quality.

Applying the target calculation is used as an external information basis submitted by the users/customers about the price which is acceptable and permissible for them. On this basis, the enterprise completes inside information about organizing its production process so that it could distribute its production at the specified market price, could provide the desired quality to its customers and could achieve/make the desired profit.

The target calculation method is directed not just to calculate the production costs - it determines an acceptable level of costs in which the prime cost of the product is such that it satisfies the needs of the customer on one hand, on the other - the needs of the company's management for a certain level of profit.

Concerning technology, it is important to emphasize that this is a method by which the costs are calculated before they are made. Thus the current information is used for planning and controlling the production process. The costs are planned before they are made and before the product is introduced into production, i.e. at the stage of development and design. This allows to respond adequately to costs higher than expected and to change the product design in a short time in order to reduce the cost and make expected profits at consumer-level price and quality.

The target calculation can be considered as a way to reduce the time for which the product passes over from the first stage of production to consumers - by eliminating activities that do not add value and by improving productivity. By this method the product life cycle could be signiticantly reduced.

\section{Structure of the system of target calculation}

From a structural point of view the system of target calculation is constructed by interrelated and interdependent activities executed simultaneously. These activities can be divided into two groups:

- for establishing the target costing;

- for completing the target calculation.

\footnotetext{
${ }^{3}$ S. Anstri, A template for implementing Target costing, Cost Management; Sep/Oct 2006; 20, 5; ABI/INFORM Global, p. 20-27
} 
The first group of activities is associated with obtaining information from the external business environment, establishing market niches and regulating product concepts according to customer requirements. These stages are the following: market research; competitor analysis; product or customer niche; customer requirements; product characteristics and market price.

After taking into account the product or customer niche, analyzing the market and competitors the enterprise sets a market segment, i.e. it specifies a group of clients, among whom it intends to distribute its production. For the market of banking services the major segments can be summarized as follows: multinational banks; inland banks; specialized banks; investment banks; non-bank institutions; branches of foreign banks.

The second group of activities is associated with costs calculations, analysis and comparison of the allowable costs with those obtained by the calculations and, if necessary, search for a better alternative. If the first group of activities lays the emphasis only to meeting customer needs, the second one is linked with the interests of the company's management. The stages of completing the target calculation are as follows:

1. Determine the level of desired profit - it is determined by the enterprise management and its size depends on the amount of admissible costs to produce the product.

2. Determine the eligible costs - by subtracting the desired profit from the market price of the test product. The term "the permitted allowable cost" is also used.

3. Determine the current value of the product - it shows the costs that would have been done to produce a trial product when implementing existing design, specifications and production technologies. It is also called the evaluated resulting value.

4. Compare the resulting value with the target value - establish whether the two values are equal or there are differences. If they match, the product manufacturing starts. However, if the resulting production costs exceed the allowable ones, then the next stage has to be moved to.

5. Repeat the cost analysis, if necessary, to reduce the value - changes in the product design, or technology, or one of the production processes in order to preserve the test product quality, but reduce the cost of its production.

All these activities that make up the process of the target calculation are carried out at three levels ${ }^{4}: a$ market level, a product level and a component level.

\section{Strategic aspects of the target calculation}

The strategic aspects of the target calculation can be summarized as follows:

- The method allows managers to provide competitive advantage to the enterprise, trying to satisfy the maximum needs of its customers. Analyzing the information obtained through the method of target calculation, it is important to consider that the target price should not be achieved through the removing some of the product features that customers like, reducing the performance and reliability of the product or delaying its introduction to the market. The only way to produce the product with the specified characteristics and market price, ensuring the expected profit is by removing activities that do not add value at the expense of those that add such value.

- The analysis of the value chain is included in the range of management accounting for strategic decisions and gives an opportunity for disclosing the sources of competitive advantage. The successful implementation of the system of target calculation is based on longstanding and strong relationships with all the participants in the value chain. To do it a good communication and cooperation of the economic unit with all the chain units should be ensured. Suppliers, distributors, dealers, customers and many others actively participate in the implementation process of the target calculation and help for focusing on cost reduction. It can be generalized that the method unites the organization and its external partners in a system - suppliers, customers and supports a system for planning the cost and profit.

- The target calculation is a tool for continuous improvement of the product carried out during the design process. The product design and the processes related to it are key points in the efforts to reduce costs by the target calculation. The method designs the product together with its manufacturing process and delivery at the first stage of the product life cycle. The advantage of this method comes from the fact that this first stage provides most of the costs included in the prime cost of the product and at the same time, a very small part of them are actually made at this stage. Following this logic, it can be concluded that the costs are more easily managed when designing, than when performed. This allows responding adequately if higher than expected costs are obtained, changing the product design in a short time in order to reduce the cost and reaching the expected profits keeping specified consumer-level price and quality. The target calculation is not only the method of calculation, but also a strategic planning method.

- The Management accounting for strategic decisions provides information about the product lifecycle and product range. Calculation the lifecycle covers the costs associated with owning a specific product

\footnotetext{
${ }^{4}$ Cooper, R., Slagmulder, R., Target Costing and Value Engineering. Productivity Press, Portland OR, 1997

DOI: $10.9790 / 487 X-1809027780 \quad$ www.iosrjournals.org $\quad 79 \mid$ Page
}


throughout its usable life. The goal is to minimize the so-called "cost of ownership" which includes the market price of the product, the maintenance and repair costs and costs associated with removal of the product at the end of its usable life and other.

- The method allows optimizing the ratio between costs and products and services quality and optimizing the technological processes within the economic unit. For example, search for alternative resources to ensure the effective running of the process, as well as more rational use of resources necessary for functioning of the management system.

- At a strategic level the target calculation is used for making decisions about reorganization of economic unit, modifing the assortment of products and services, exiting to new markets, diversification and other. Reorganization of various activities leads to increased productivity by highlighting the opportunities to increase the effectiveness of their implementation as well as to finding out the causes of unproductive costs and the ways of their elimination.

The target calculating method is not only computational procedure, but a means for achieving competitive advantage. It helps the company to improve product quality, to reduce delivery time and to reduce costs by removing activities that do not add value.

\section{Conclusion}

The target calculating method is not only computational procedure, but a means for achieving competitive advantage. It helps the company to improve product quality, to reduce delivery time and to reduce costs by removing activities that do not add value.

\section{References}

[1] M. Pavlova, The activity of universities in a competitive environment and the role of management accounting, University Publishing House "St. St. Cyril and Methodius", Veliko Turnovo, 2012

[2] S. Anstri, A template for implementing Target costing. Cost Management, Sep/Oct 2006, 20, 5, ABI/INFORM Global, pp. 20-27

[3] R. Cooper, R. Slagmulder, Target Costing and Value Engineering. Productivity Press, Portland OR, 1997

[4] S. Anstri, Target Costing: The Next Frontier in Strategic Cost Management. Irwin Professional Pub, 1997

[5] R. Cooper, R. Slagmulder, Develop Profitable new product with target costing. Sloan Management Review, Vol. 40, N. 4, 1999 , pp. 23-33 